\title{
Gelatinized and Non-Gelatinized Corn Starch Based Diet Influence the Fatty Acid Profile in the Liver of Tropical Freshwater Fish, Labeo Rohita
}

\author{
Vikas Kumar ${ }^{1,2 *}$, N.P. Sahu², A.K. Pal' ${ }^{2}$ K. K Jain², Shivendra Kumar ${ }^{2,3}$, Vidya Sagar ${ }^{2}$, Amit K. Sinha ${ }^{4}$ and Jayant Ranjan ${ }^{5}$ \\ ${ }^{1}$ Institute for Animal Production in the Tropics and Subtropics (480b), University of Hohenheim, Stuttgart, 70599, Germany. \\ ${ }^{2}$ Division of Fish Nutrition and Biochemistry, Central Institute of Fisheries Education, Versova, Mumbai-400061, India. \\ ${ }^{3}$ Krishi Vigyan Kendra, Madhopur - 845454, Rajendra Agricultural Univeristy, Pusa, Bihar, India. \\ ${ }^{4}$ Laboratory for Ecophysiology, Biochemistry and Toxicology, University of Antwerp, Groenenborgerlaan 171, 2020 Antwerp, Belgium \\ ${ }^{5}$ Laboratory of Aquaculture and Artemia Reference centre, Department of Animal Production, Ghent University, 9000 Gent, Belgium
}

\begin{abstract}
Sixty days feeding trial was conducted to study the influence of gelatinized (G) to non-gelatinized (NG) starch ratio in the diet on fatty acids profiles and lipid profile in Labeo rohita fingerlings. Two hundred and thirty four fingerlings (average weight $2.53 \pm 0.04 \mathrm{~g}$ ) were randomly distributed into six treatments with each of three replicates. Six semi purified diets either containing NG and/or $\mathrm{G}$ cornstarch $(42.4 \%)$ were fed to respective group. Total saturated fatty acids in liver increased with the increasing level of $\mathrm{G}$ starch in the diet whereas reverse trend observed for monounsaturated fatty acids. Total $n-3$ fatty acids decreased linearly with the increasing level of $\mathrm{G}$ starch in the diet. Among the n-3 fatty acids linolenic acids content was more in NG starch fed group. Similarly, eicosapentaenoic acid contents gradually decreased with increasing level of $G$ starch content. The $n-6 / n-3$ ratio was higher in $G$ starch fed groups compared to NG starch fed group. Total lipid content and triglyceride levels in muscle and liver increased linearly with the increasing level of $\mathrm{G}$ starch, whereas phospholipid and cholesterol level in muscle and liver tissue exhibited opposite trend. Conclusively, n-3 fatty acids deposition in liver of fish were higher in NG starch fed groups compared to G starch fed group.
\end{abstract}

Keywords: Starch; total lipid; cholesterol; phospholipid; fatty acids; Labeo rohita

\section{Introduction}

In this modern era of hasty life, health consciousness is increasing among the people. These results in diversion of animal nutritionist towards the improvement of product quality beside the growth of the animal. In this endeavour incorporation of essential fatty acid (EFA) in our routine diet may be an ideal approach. They are essential nutrient of dietary food for normal growth and development. Considering its significance, strategies for enhancing the n-3 fatty acids content is being formed for quality improvement of the animal product. Besides, deficiency of EFA cause several changes in lipid metabolism which include hepatic synthesis of fatty acids, excessive deposition of triacylglycerol (TG) and cholesterol esters in liver, lower concentrations of TG and cholesterol in plasma.

However, fish is considered to the best natural source of EFA but the amount varies among fresh water and marine species. Former is rich in n-6 fatty acid while latter contains more n-3 fatty acid. In spite less n-3 fatty acids contents of freshwater fish, in comparison to marine fish, some molecular approach has been initiated to enhance the $\mathrm{n}-3$ fatty acids content, mainly by inserting desaturase gene into freshwater fishes $[1,2]$. But till date no promising result has been documented. Pragmatically with respect to it, dietary manipulation approach may surpass the gene manipulation approach. This operation requires a deliberate investigation of organ responsible for catalysing lipid metabolic activities. Indeed in fish, liver is the chief organ for the synthesis of long chain fatty acids and plays a critical role in various aspects of lipid metabolism such as the uptake, oxidation and conversion of fatty acids and the supply of long-chain poly unsaturated fatty acid (PUFA) to other tissues [3,4]. Thus, the analysis of the lipid contents and the fatty acid profiles of liver and muscle tissue from fish can yield valuable information, which may help to elucidate their nutritional lipid requirements and thus optimal feed can be formulated which in turn will have beneficial effect on consumer. Fish is a rich source of polyunsaturated fatty acids (PUFA) namely, n-6 and n-3 PUFA, which are beneficial to health. The n-3 PUFA are considered as cardio-protective, anti-atherosclerotic, antithrombotic and anti-arrythmitic [5]. Studies with non-human primates and human newborns indicate that Docosahexaenoic acid (DHA) is essential for the normal functional development of the retina and brain, particularly in premature infants [5]. Arachidonic acid (AA), the PUFA of n-6 series is a precursor of biologically important products such as epoxides, AAethanolamide, anadamide iso-prostanes, isomers of prostaglandin [5]. Nevertheless [5] has established the lipids and fatty acids profile of Indian major carps for both muscle and liver. Fatty acids profile of muscle in relation to dietary fatty acids has already been established [1], but its relation with other nutrients like carbohydrate has not been established especially in fish, which may be helpful for the nutritionist for their product quality improvement programme. Therefore, there is a immense need to understand the impact of cheap dietary nutrients like carbohydrate on muscle and liver lipid profile to uplift the nutritional value of fish, that too at low cost. This may be an excellent approach of producing good quality fish product at economical cost. Furthermore digestion and metabolization of lipid serves better as an energy source for protein sparing than carbohydrate. Also the protein sparing effect of lipid varies between species [6].

Unlike mammals, dietary carbohydrate is less utilized in fish due to their inherit low ability to utilize carbohydrate [7-10]. But herbivorous fish like L. rohita has high potential to utilize more carbohydrate in their diet [11-17]. Carbohydrate is widely included in fish feed to improve their physical quality and to provide an inexpensive non-nitrogenous

*Corresponding authors: Vikas Kumar, Department of Aquaculture System and Animal Nutrition in the Tropics and Subtropics (480b), University of Hohenheim Stuttgart, 70599, Germany, Tel. +49-71145923646; Fax. +49-71145923702 E-mail: vikaskr2005@rediffmail.com

Received December 27, 2010; Accepted January 26, 2011; Published January 28, 2011

Citation: Kumar V, Sahu NP, Pal AK, Jain KK, Kumar S, et al. (2011) Gelatinized and Non-Gelatinized Corn Starch Based Diet Influence the Fatty Acid Profile in the Liver of Tropical Freshwater Fish, Labeo Rohita. J Aquac Res Development 2:106 doi:10.4172/2155-9546.1000106

Copyright: ( $2011 \mathrm{Kumar} V$, et al. This is an open-access article distributed unde the terms of the Creative Commons Attribution License, which permits unrestricted use, distribution, and reproduction in any medium, provided the original author and source are credited. 
energy source. Dietary level of carbohydrate in commercial feed for fish ranges from $5-50 \%$ depending on the species and life stage [18]. The carbohydrate digestibility in fish depends on the dietary inclusion level and the processing treatments applied to it (raw/coocked/extruded) as reported for carp, Cyprinus carpio [19]. Moreover [11] had reported a significant increase in the available carbohydrate and its digestibility with increasing level of gelatinized (G) starch in the diet of Labeo rohita fry, which favours lipogenesis and further lead to an increased proportion of saturated fat [20]. On contrary [21] reported a significant increased in liver n-3 fatty acid content when Ayu (Plecoglossus altivelis) were fed with non gelatinized (NG) starch.

Thus the aim of this study was to investigate the effect of the gelatinized or non-gelatinized starch source on the fatty acid profile of liver of L. rohita.

\section{Materials and Methods}

\section{Experimental design}

Labeo rohita fingerlings were procured from Palgarh fish farm in Maharashtra, were acclimatized to the experimental condition for 20 days. Two hundred thirty four juveniles of uniform size (avg. wt. 2.53 $\pm 0.04 \mathrm{~g}$ ) were randomly distributed in six experimental groups with each of three replicates in a plastic tank of $150 \mathrm{l}$ capacity $(80 \times 57 \times$ $42 \mathrm{~cm}$ ) following a completely randomized design (CRD). Aeration was provided for $24 \mathrm{~h}$ in all the experimental tanks. Feed was given at $2.5 \%$ of the body weight for 60 days, twice in day at 8:00 and 18:00 $\mathrm{h}$ under normal light regime (light/dark: $12 / 12 \mathrm{~h}$ ). Uneaten feed and faecal matters were siphoned out daily with about $75 \%$ water exchange. The physico-chemical parameters of water were maintained within the optimum range (dissolve oxygen: $5.4-6.5 \mathrm{mg} / \mathrm{l} ; \mathrm{pH}$ : $7.7-8.1$; temperature: $27-29^{\circ} \mathrm{C}$; ammonia nitrogen: $0.15-0.22 \mathrm{mg} / \mathrm{l}$; nitrite nitrogen: $0.001-0.003 \mathrm{mg} / \mathrm{l}$; nitrate nitrogen: $0.01-0.003 \mathrm{mg} / \mathrm{l}$ ) as required for the Labeo rohita fingerlings.

\begin{tabular}{|l|c|}
\hline Ingredient & \% Inclusion \\
\hline Casein $^{\mathrm{a}}$ & 30.57 \\
\hline Gelatin $^{\mathrm{b}}$ & 8.00 \\
\hline Corn Flour(NG or G) $^{\mathrm{c}}$ & 42.43 \\
\hline Cellulose $^{\mathrm{d}}$ & 7.00 \\
\hline Sunflower oil : Cod liver Oil (2:1) & 8.00 \\
\hline Carboxymethyl Cellulose $^{\mathrm{e}}$ & 1.00 \\
\hline $\begin{array}{l}\text { Vitamin }+ \text { Mineral Mix } \\
\text { (EMIX PLUS) }\end{array}$ & 2.60 \\
\hline Vitamin-C $^{\mathrm{f}}$ & 0.10 \\
\hline Vitamin B Complex $^{\mathrm{h}}$ & 0.10 \\
\hline Glycine $^{\mathrm{i}}$ & 0.20 \\
\hline BHT $^{\mathrm{j}}$ & 0.02 \\
\hline
\end{tabular}

NG - Non gelatinized, G - Gelatinized

a: Casein fat free, $79.5 \% \mathrm{CP}$ (HiMedia Ltd, India).

b: Gelatin, $95.7 \%$ CP (HiMedia Ltd, India).

c: Procured from a local market (Mumbai, India).

d: Sd Fine Chemicals Ltd., India.

e: Sd Fine Chemicals Ltd., India.

f: Composition of vitamin mineral mix (EMIX PLUS) (quantity/2.5 kg): vitamin A $5,500,000$ IU; vitamin D3 1,100,000 IU; vitamin B2 $2000 \mathrm{mg}$; vitamin E $750 \mathrm{mg}$; vitamin K $1000 \mathrm{mg}$; vitamin B6 $1000 \mathrm{mg}$; vitamin B12 $6 \mathrm{mg}$; calcium pantothenate $2500 \mathrm{mg}$; nicotinamide $10 \mathrm{~g}$; choline chloride $150 \mathrm{~g}$; Mn 27,000 mg; I $1000 \mathrm{mg}$; Fe 7500 mg; Zn 5000 mg; Cu 2000 mg; Co 450 mg; Ca 500 g; P 300 g; L-lysine, $10 \mathrm{~g}$; DL-methionine $10 \mathrm{~g}$; selenium $50 \mathrm{ppm}$.

g: Stay C (Hoffman La Roche, Nutley, NJ, USA) 15\% ascorbic acid activity

h: Composition of vitamin B complex (quantity/g). Thiamine mononitrate 20 $\mathrm{mg}$; riboflavin $20 \mathrm{mg}$; pyridoxine hydrochloride $6 \mathrm{mg}$; vitamin B12 $30 \mathrm{mcg}$; niaciamide $200 \mathrm{mg}$; Ca pantothenate $100 \mathrm{mg}$; folic acid $3 \mathrm{mg}$; biotin $200 \mathrm{mcg}$

i: HiMedia Itd, India.

j: Sd Fine Chemicals Ltd., India.

Table1: Composition of the experimental diets (\% dry matter).

\begin{tabular}{|l|l|l|l|l|l|}
\hline Treatments & $\begin{array}{l}\text { Organic } \\
\text { Matter }\end{array}$ & $\begin{array}{l}\text { Crude } \\
\text { Protein }\end{array}$ & $\begin{array}{l}\text { Total } \\
\text { carbohydrate }\end{array}$ & $\begin{array}{l}\text { Ether } \\
\text { Extract }\end{array}$ & Ash \\
\hline T1 & 96.16 & 35.99 & 49.72 & 10.45 & 3.84 \\
\hline T2 & 96.03 & 36.22 & 49.83 & 9.97 & 3.97 \\
\hline T3 & 96.03 & 35.91 & 50.06 & 10.05 & 3.97 \\
\hline T4 & 96.34 & 35.94 & 50.36 & 10.04 & 3.66 \\
\hline T5 & 96.45 & 35.95 & 50.35 & 10.15 & 3.55 \\
\hline T6 & 96.16 & $36.12 \pm 0.15$ & 50.00 & 10.04 & 3.84 \\
\hline
\end{tabular}

Table 2: Proximate composition of different experimental diets (\% DM) fed to Labeo rohita fingerlings during experiment period of 60 days.

\section{Gelatinization of corn and preparation of diet}

The fine powder corn was made into dough by the addition of the required amount of water, followed by cooking in an autoclave at 15 psi. for $1 \mathrm{~h}$ to achieve maximum gelatinization. The cooked corn was then spread over a tray and dried in an oven at $60^{\circ} \mathrm{C}$. The dried mass was pulverized in a hammer mill with a $0.5 \mathrm{~mm}$ screen and stored in airtight containers until required.

In this experiment $42.43 \%$ corn flour was used as carbohydrate source either as gelatinized (G) or, nongelatinized (NG) form. Six isoproteinous and isocaloric semi-purified diets were prepared with two types of corn flour like non-gelatinized (NG) and gelatinized $(\mathrm{G})$ each at six levels of inclusion $(0,20,40,60,80,100 \%)$ viz., T1 (100\% NG, and $0 \%$ G starch), T2 (80\% NG, and 20\% G starch), T3 (60\% NG, and $40 \%$ G starch), T4 (40\% NG, and 60\% G starch), T5 (20\% NG, and $80 \%$ G starch), T6 (0\% NG and $100 \%$ G starch) Table 1. All the ingredients were thoroughly mixed with water to make dough except the vitamin mineral mix. The dough was then kept for $1 \mathrm{~h}$ for proper conditioning followed by steaming for $5 \mathrm{~min}$ in a pressure cooker. After cooling the dough, vitamin mineral mix were mixed properly and pressed through a hand pelletiser with a sieve size of $2 \mathrm{~mm}$ diameter to prepare the pellet. Finally the pellets were dried at $40^{\circ} \mathrm{C}$ and stored at $4^{\circ}$ $\mathrm{C}$ until use. The proximate composition of all the diets were determined by the standard methods of the AOAC [22] (Table 2).

\section{Sampling}

After completion of the feeding trial of 60 days, the sampling was carried out for the analysis of lipid and fatty acid profiles. Nine $(3 \times 3)$ fishes from each treatment were anaesthetized with clove oil $(50 \mathrm{ml}$ $\mathrm{L}^{-1}$ ) and the targeted organs were dissected out. One fish per group (replicate) was carefully dissected to isolate muscle and liver and stored at $-20{ }^{\circ} \mathrm{C}$ for determination of total lipids, total phospholipids, total cholesterol and total triglycerides. Fatty acids analysis has been done for liver of fish according to AOAC [22].

\section{Extraction of tissue lipids, preparation of fatty acid methyl esters (FAME) and fatty acids analysis}

The fishes were dissected; muscle and liver were cut out. Muscle was taken out from the lateral side of fish. The lipid was extracted from the liver and muscle as described by [23]. The tissue was homogenized with chloroform: methanol mixture (2:1) and transferred into a $25 \mathrm{ml}$ graduated stopped measuring cylinder. The contents were allowed to stand for $6 \mathrm{~h}$, with occasional shaking. The mixture was then filtered through Whatman No. 42 paper.

The residues were transferred into the cylinder and again chloroform: methanol $(2: 1)$ mixture was added. The contents were held for two hours with occasional shaking. The mixture was filtered as before and both the filtrates were combined. The residue was discarded. The filtrate was then treated with 0.2 vol. of chilled normal saline and the whole content was transferred to a separating funnel. Mixing was 
done gently, and the separating funnels were held vertically until the two phases were clearly separated. The upper layer was discarded. The salt treatment was repeated twice. The lower layer was transferred into a pre-weighed conical flask and the solvent was evaporated off by continuous flow of nitrogen. The flask was weighed again. The residue was dissolved in chloroform $\left(2 \mathrm{mg} \mathrm{ml}^{-1}\right)$, and used for further analysis [23].

The AOAC [22] method was followed to esterify the lipid extract. FAME's were prepared from the isolated lipids by heating with the methanolic $\mathrm{NaOH}$ followed by $\mathrm{BF}_{3}$ methanol for esterification. Five $\mathrm{ml}$ of $\mathrm{n}$-heptane was added to recover the methyl esters in organic phase. The mixture was washed with saturated $\mathrm{NaCl}$ solution and two phases were separated by using a separating funnel. The upper $n$-heptane phase was pipetted out and stored in a $10 \mathrm{ml}$ glass vials with teflon lid until further analysis.

The Fatty acid methyl ester (FAME) was analyzed by GC-MS QP2010 (quadruple mass-spectrometer with ionization energy of $70 \mathrm{eV}$ ) equipped with $\mathrm{dB}$-wax column of $25 \mathrm{~mm}: 0.25 \mu \mathrm{m}$ film thickness with helium gas as carrier gas. The sample was injected at split mode injection port at $1: 15$ split ratio at $250^{\circ} \mathrm{C}$ and oven temperature was programmed from $50-230^{\circ} \mathrm{C}$ at the rate of $10^{\circ} \mathrm{C} / \mathrm{min}$. The mass spectrometer was turned to get relative abundance of $\mathrm{m} / \mathrm{Z}$ ranging from 40.00 to 550.00 . The values of fatty acids were presented in area percentage of total identified fatty acids.

\section{Determination of total lipids, total phospholipids, total cholesterol and total triglycerides}

Total lipid was estimated spectrophotometrically by Charring procedure described by Marsh and Winstein [24]. $0.1 \mathrm{ml}$ of aliquot (lipid extract) was taken in a test tube and the chloroform was evaporated by passing nitrogen gas. The tubes were then cooled and $2 \mathrm{ml}$ of concentrated $\mathrm{H}_{2} \mathrm{SO}_{4}$ was added to each of the tubes. The tubes were then placed in the aluminium block at $200^{\circ} \mathrm{C}$ for $15 \mathrm{~min}$. The tubes were removed and were kept at room temperature for $15 \mathrm{sec} .3 \mathrm{ml}$ of distilled water was added by placing the tubes in ice bath followed by keeping them at room temperature for $10 \mathrm{~min}$. The OD was recorded at $375 \mathrm{~nm}$.

The total phospholipid in the tissue was estimated as per the procedure described by [25]. An aliquot $(0.1 \mathrm{ml})$ of lipid extract was taken in a test tube and $0.4 \mathrm{ml}$ of $60 \%$ perchloric acid solution was added. The tube was then held in heated aluminium block $\left(180^{\circ} \mathrm{C}\right)$ for 2 h. $5 \mathrm{ml}$ of the colouring reagent (8 parts of $5.5 \%$ perchloric acid; 1 part of $2.5 \%$ ammonium molybdate solution and 1 part of $10 \%$ ascorbic acid) were added. The tubes were transferred to a thermostatic water bath $\left(37^{\circ} \mathrm{C}\right)$ for $2 \mathrm{~h}$. The OD was recorded at $650 \mathrm{~nm}$. The value of Pi was multiplied by the factor 25 to obtain the phospholipid concentration (expressed as mg lecithin gm tissue $\mathrm{e}^{-1}$ ).

The total cholesterol in the tissue was estimated by the method [26]. $0.2 \mathrm{ml}$ aliquot of lipid extract was taken in a test tube to which $6 \mathrm{ml}$ acetic acid and $4 \mathrm{ml}$ coloring reagent were added and the contents were mixed well. The tubes were allowed to cool and the contents were mixed well. The tubes were allowed to cool and the OD was recorded at 540 $\mathrm{nm}$. Analytical grade cholesterol was used as the reference standard.

The concentration of triglycerides in the extraction was determined by subtracting the value of cholesterol and phospholipids from the total lipids.

\section{Statistical analysis}

The main effect of G and NG starch in the diet was tested by One- way ANOVA. The comparison of any two mean values was done by Duncan's multiple range test (DMRT) at $\mathrm{P}<0.05$. All the statistical analysis was done by using the software programme SPSS (version 14). Values are expressed as means \pm standard deviation.

\section{Results}

\section{Fatty acids composition}

The Fatty acid composition of experimental diet and liver tissues has been illustrated in Table 3 and Table 4 respectively. Data showed significant differences $(p<0.05)$ among the dietary treatments.

In case of liver fatty acids profile, total saturated fatty acids (SAFAs) contents increased with the increasing level of $\mathrm{G}$ starch in the experimental diet, highest content being registered in the T6 group, which is not significantly different $(p>0.05)$ to the T5 (fed with $80 \% \mathrm{G}$ and 20\% NG starch) group. Among the SAFA the palmitic (C16:0) and stearic acid (C18:0) contents were dominant over the other fatty acids. Palmitic acid content was highest in T5 group, which was similar to T6 group (fed with $100 \% \mathrm{G}$ starch) and lowest in T1 group (fed with 100\% NG starch), whereas stearic acid content was highest in T6 group (fed with $100 \% \mathrm{G}$ starch).

Monounsaturated fatty acids (MUFAs) content was similar in T1, T2, T3 and T5 groups and was lowest in T4 group. Among the MUFAs, oleic acid (C18:1) content was highest in T5 group (fed with $80 \% \mathrm{G}$ and $20 \%$ NG starch) which was similar to T1 and T3 groups and lowest in T2 group. There was a significant difference $(p<0.05)$ in total n- 6 fatty acids contents of different experimental groups. Highest total n-6 fatty acids contents was observed in T1 group (fed with $100 \%$

\begin{tabular}{|c|c|}
\hline Fatty acids & Percentage (\%) \\
\hline $\mathrm{C} 12: 0$ & 0.17 \\
\hline C14:0 & 2.86 \\
\hline C15:0 & 0.47 \\
\hline C16:0 & 9.49 \\
\hline C17:0 & 0.41 \\
\hline C18:0 & 6.92 \\
\hline $\mathrm{C} 20: 0$ & 0.71 \\
\hline C14:1n-9 & 0.04 \\
\hline C16:1n-9 & 3.59 \\
\hline C16:1n-7 & 0.11 \\
\hline C17:1n-9 & 0.35 \\
\hline C18:1n-9 & 22.45 \\
\hline C18:1n-7 & 2.21 \\
\hline$C 20: 1 n-9$ & 4.99 \\
\hline$C 20: 1 n-7$ & 0.21 \\
\hline$C 22: 1 n-9$ & 3.99 \\
\hline$C 22: 1 n-7$ & 0.53 \\
\hline C16:2n-6 & 0.53 \\
\hline C18:2n-6 & 28.37 \\
\hline$C 20: 2 n-6$ & 0.27 \\
\hline$C 20: 3 n-6$ & 0.08 \\
\hline$C 20: 4 n-6$ & 0.2 \\
\hline C18:3n-3 & 1.16 \\
\hline C18:4n-3 & 0.68 \\
\hline$C 20: 3 n-3$ & 0.1 \\
\hline$C 20: 4 n-3$ & 0.56 \\
\hline$C 20: 5 n-3$ & 3.67 \\
\hline$C 22: 5 n-3$ & 1.57 \\
\hline$C 22: 6 n-3$ & 3.31 \\
\hline$\sum$ SAFA & 21.03 \\
\hline$\sum$ MUFA & 38.47 \\
\hline$\sum n-6$ & 29.45 \\
\hline$\sum n-3$ & 11.05 \\
\hline$n-6 / n-3$ & 2.67 \\
\hline
\end{tabular}

Table 3: Fatty acids profile of the experimental diets (\%). 
Citation: Kumar V, Sahu NP, Pal AK, Jain KK, Kumar S, et al. (2011) Gelatinized and Non-Gelatinized Corn Starch Based Diet Influence the Fatty Acid Profile in the Liver of Tropical Freshwater Fish, Labeo Rohita. J Aquac Res Development 2:106. doi:10.4172/2155-9546.1000106

Page 4 of 6

\begin{tabular}{|c|c|c|c|c|c|c|}
\hline Fatty Acid & T1 & T2 & T3 & T4 & T5 & T6 \\
\hline C12:0 & $0.21^{b} \pm 0.01$ & $0.18^{\mathrm{cd}} \pm 0.01$ & $0.25^{\mathrm{a}} \pm 0.01$ & $0.17^{c d} \pm 0.01$ & $0.17^{d} \pm 0.01$ & $0.19^{c} \pm 0.01$ \\
\hline C14:0 & $1.51^{\mathrm{c}} \pm 0.02$ & $1.81^{a} \pm 0.04$ & $1.27^{d} \pm 0.06$ & $1.46^{c} \pm 0.01$ & $1.64^{b} \pm 0.02$ & $1.71^{b} \pm 0.02$ \\
\hline C15:0 & $1.09^{a} \pm 0.09$ & $0.71^{\mathrm{ab}} \pm 0.01$ & $0.54^{c} \pm 0.08$ & $0.57^{c} \pm 0.03$ & $0.59^{c} \pm 0.01$ & $0.82^{b} \pm 0.01$ \\
\hline C16:0 & $15.25^{e} \pm 0.04$ & $16.54^{d} \pm 0.23$ & $17.83^{c} \pm 0.48$ & $20.10^{b} \pm 0.04$ & $21.06^{a} \pm 0.24$ & $20.45^{\mathrm{ab}} \pm 0.17$ \\
\hline C17:0 & $1.88^{a} \pm 0.02$ & $1.57^{c} \pm 0.01$ & $1.31^{e} \pm 0.05$ & $1.49^{c} \pm 0.01$ & $1.40^{d} \pm 0.03$ & $1.78^{b} \pm 0.02$ \\
\hline C18:0 & $6.32^{\mathrm{e}} \pm 0.02$ & $7.00^{d} \pm 0.12$ & $5.85^{f} \pm 0.12$ & $8.64^{b} \pm 0.05$ & $8.25^{\mathrm{c}} \pm 0.08$ & $8.93^{a} \pm 0.02$ \\
\hline $\mathrm{C} 20: 0$ & $0.36^{\mathrm{cd}} \pm 0.01$ & $0.42^{b} \pm 0.02$ & $0.30^{e} \pm 0.01$ & $0.34^{d} \pm 0.01$ & $0.47^{a} \pm 0.02$ & $0.39^{b c} \pm 0.02$ \\
\hline C16:1 & $4.87^{c} \pm 0.09$ & $6.23^{a} \pm 0.10$ & $6.05^{a} \pm 0.04$ & $4.35^{d} \pm 0.06$ & $5.29^{b} \pm 0.05$ & $5.28^{b} \pm 0.02$ \\
\hline C18:1 & $33.53^{a b} \pm 1.23$ & $30.44^{c} \pm 2.12$ & $32.14^{\mathrm{abc}} \pm 1.26$ & $31.30^{c} \pm 1.65$ & $34.07^{a} \pm 2.02$ & $31.61^{b c} \pm 1.05$ \\
\hline $\mathrm{C} 20: 1$ & $3.51^{b} \pm 0.03$ & $4.42^{a} \pm 0.06$ & $4.45^{a} \pm 0.10$ & $3.60^{b} \pm 0.06$ & $3.23^{c} \pm 0.09$ & $3.16^{c} \pm 0.02$ \\
\hline $\mathrm{C} 22: 1$ & $1.47^{a} \pm 0.02$ & $1.56^{a} \pm 0.10$ & $1.46^{a} \pm 0.03$ & $0.92^{\mathrm{c}} \pm 0.01$ & $1.21^{b} \pm 0.02$ & $1.24^{b} \pm 0.01$ \\
\hline C18:2 n-6 & $23.19^{a} \pm 0.97$ & $19.80^{b} \pm 0.45$ & $19.69^{b} \pm 0.32$ & $18.45^{\mathrm{bc}} \pm 0.24$ & $17.03^{\text {cd }} \pm 0.15$ & $16.91^{d} \pm 0.17$ \\
\hline$C 20: 4 n-6$ & $2.30^{c} \pm 0.01$ & $4.35^{\mathrm{ab}} \pm 0.03$ & $4.28^{b} \pm 0.08$ & $4.53^{a} \pm 0.03$ & $2.17^{c} \pm 0.08$ & $4.17^{b} \pm 0.09$ \\
\hline$C 22: 5 n-6$ & $0.13^{d} \pm 0.01$ & $0.72^{\mathrm{a}} \pm 0.02$ & $0.60^{\mathrm{ab}} \pm 0.04$ & $0.51^{\mathrm{ab}} \pm 0.01$ & $0.29^{c d} \pm 0.01$ & $0.43^{b c} \pm 0.02$ \\
\hline C18:3n-3 & $0.38^{\mathrm{ab}} \pm 0.02$ & $0.42^{a} \pm 0.03$ & $0.35^{b} \pm 0.01$ & $0.39^{\mathrm{ab}} \pm 0.01$ & $0.23^{d} \pm 0.01$ & $0.29^{c} \pm 0.01$ \\
\hline$C 20: 5 n-3$ & $0.75^{a} \pm 0.02$ & $0.75^{a} \pm 0.02$ & $0.71^{\mathrm{a}} \pm 0.03$ & $0.48^{b} \pm 0.01$ & $0.36^{c} \pm 0.01$ & $0.25^{d} \pm 0.01$ \\
\hline$C 22: 6 n-3$ & $3.26^{a} \pm 0.03$ & $3.08^{b} \pm 0.02$ & $2.91^{\mathrm{c}} \pm 0.02$ & $2.68^{d} \pm 0.02$ & $2.54^{\mathrm{e}} \pm 0.01$ & $2.40^{f} \pm 0.02$ \\
\hline SAFA & $26.60^{d} \pm 0.14$ & $28.23^{c} \pm 0.19$ & $27.35^{d} \pm 0.56$ & $32.77^{b} \pm 0.88$ & $33.58^{\mathrm{ab}} \pm 036$ & $34.26^{\mathrm{a}} \pm 0.65$ \\
\hline MUFA & $43.38^{a} \pm 1.13$ & $42.65^{\mathrm{ab}} \pm 2.31$ & $44.10^{a} \pm 1.55$ & $40.18^{c} \pm 1.10$ & $43.79^{a} \pm 1.36$ & $41.28^{b c} \pm 1.16$ \\
\hline$n-6$ & $25.62^{\mathrm{a}} \pm 0.97$ & $24.87^{\mathrm{ab}} \pm 0.47$ & $24.58^{\mathrm{ab}} \pm 0.52$ & $23.50^{\mathrm{b}} \pm 0.19$ & $19.50^{d} \pm 0.11$ & $21.51^{c} \pm 0.15$ \\
\hline$n-3$ & $4.39^{a} \pm 0.06$ & $4.25^{b} \pm 0.04$ & $3.97^{c} \pm 0.03$ & $3.55^{d} \pm 0.02$ & $3.13^{e} \pm 0.03$ & $2.94^{f} \pm 0.03$ \\
\hline$n-6 / n-3$ & $5.83^{d} \pm 0.14$ & $5.86^{d} \pm 0.06$ & $6.18^{c} \pm 0.14$ & $6.61^{b} \pm 0.09$ & $6.23^{c} \pm 0.04$ & $7.32^{a} \pm 0.04$ \\
\hline
\end{tabular}

Values are mean $(n=3) \pm$ standard deviation.

Mean values in the same column with different superscript differ significantly $(p<0.05)$

Table 4: Fatty acids profile (\%) of the liver of Labeo rohita fingerlings fed with different experimental diets.

NG starch), which was similar to T2 and T3 groups and lowest in T5 groups. Among total n-6 fatty acids contents, linoleic acids (C18:3n-3) decreased with the increasing level of $G$ starch in the experimental diet, highest content being registered in the T1 group (fed with $100 \%$ NG starch) and lowest in T6 group (fed with $80 \% \mathrm{G}$ starch), whereas arachidonic acid (C20:4n-6) content was highest in T4 group. However there was no significant difference $(p>0.05)$ among T4 and T2 group and was lowest in $\mathrm{T} 5$ group.

Total n-3 fatty acids decreased linearly with the increasing level of $\mathrm{G}$ starch in the experimental diet. Highest content of $n-3$ fatty acids was reported in T1 group (fed with 100\% NG starch) and lowest in T6 group (fed with $100 \% \mathrm{G}$ starch). Among the $\mathrm{n}-3$ fatty acids linolenic acids (C18:3 n-3) content was more in NG starch fed groups than the G starch fed groups. Similarly eicosapentaenoic acid (EPA, C20:5n-3) and docosahexaenoic acid (DHA, C22:6 n-3) content gradually decreased with increasing level of $G$ starch in the diet. However the ratio of $\mathrm{n}-6 / \mathrm{n}-3$ content was highest in T6 group (fed with $100 \% \mathrm{G}$ starch) and lowest in $\mathrm{T} 1$ and $\mathrm{T} 2$ groups.

\section{Liver and muscle lipid profile}

Total lipid content, phospholipids, Cholesterol and triglycerides content of liver and muscle of $L$. rohita juveniles fed with different test diets are summarized in (Figure1, Figure 2, Figure 3 and Figure 4). Data elucidates that lipid and derivatives showed significant $(p<0.05)$ differences among the dietary treatments. Total lipid content in muscle and liver increased linearly with increase in G content of diet. However highest value in both organ was reported in T6 (feed with 100 \% G). On the contrary phospholipid content in liver and muscle decreased with increase in $\mathrm{G}$ level. A highest value was being recorded in T1 (fed with $0 \% \mathrm{G}$ ) group and lowest in T6 group (fed with 100\%). Moreover same result was documented for cholesterol level in muscle and liver. There was significant increase $(p<0.05)$ in triglycerides content in liver and muscle of $L$. rohita juvenile after feeding the diet supplemented with $100 \%$ G. Highest value in muscle as well as in liver was obtained in T6 group.

\section{Discussion}

Highest $(p<0.05)$ growth performance and nutrient utilization parameters were observed for T6 group which is statistically not different to T2 and T5 groups but higher than control (100\% NG starch) and other groups [16]. The present data demonstrate that $\mathrm{G}$ starch is better utilized by L. rohita fingerlings compared to NG starch [16].

Result from present study demonstrated that there was a significant change in fatty acids profile of liver of $L$. rohita in response to different

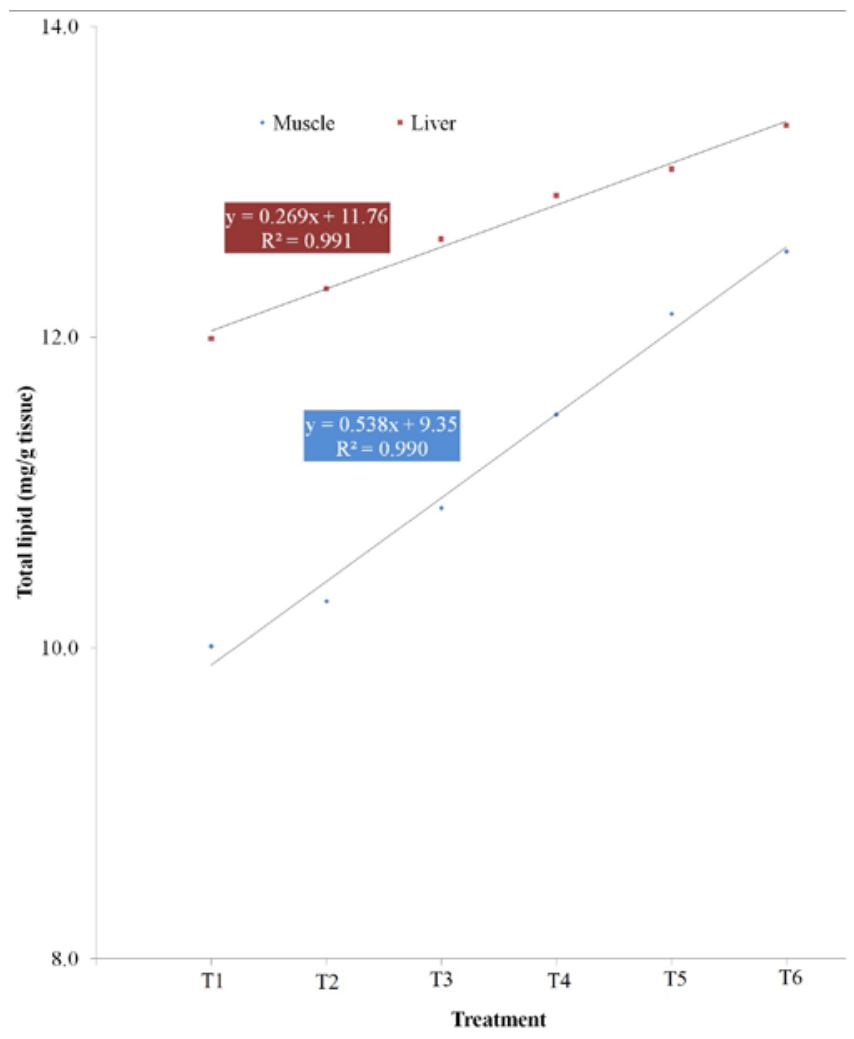

Figure 1: Total lipid ( $\mathrm{mg} / \mathrm{g}$ tissue) in muscle and liver of $L$. rohita fingerling fed with different experimental diet. 


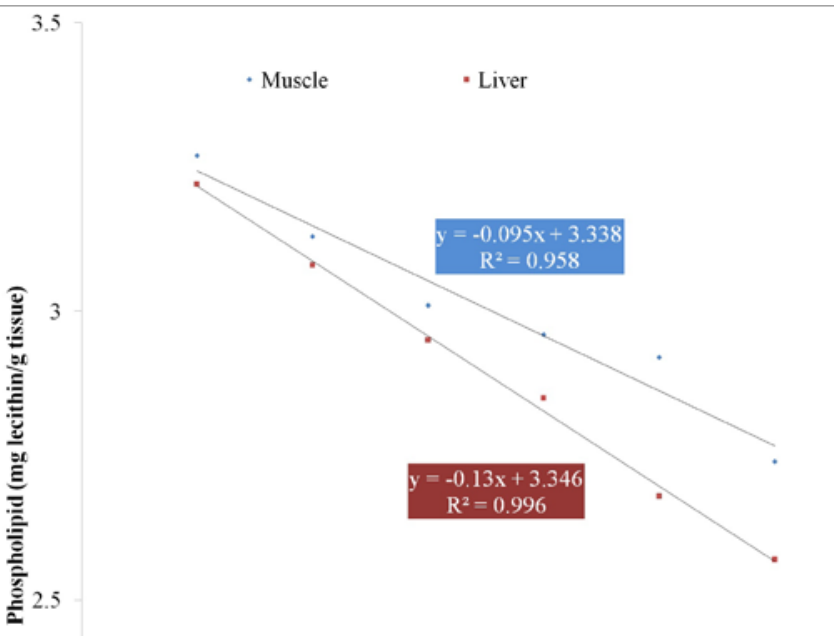

$\begin{array}{ccccccc}2 & \text { T1 } & \text { T2 } & \text { T3 } & \text { T4 } & \text { T5 } & \text { T6 } \\ & & & & \end{array}$

Figure 2: Phospholipid (mg lecithin/g tissue) in muscle and liver of L. rohita fingerling fed with different experimental diet.

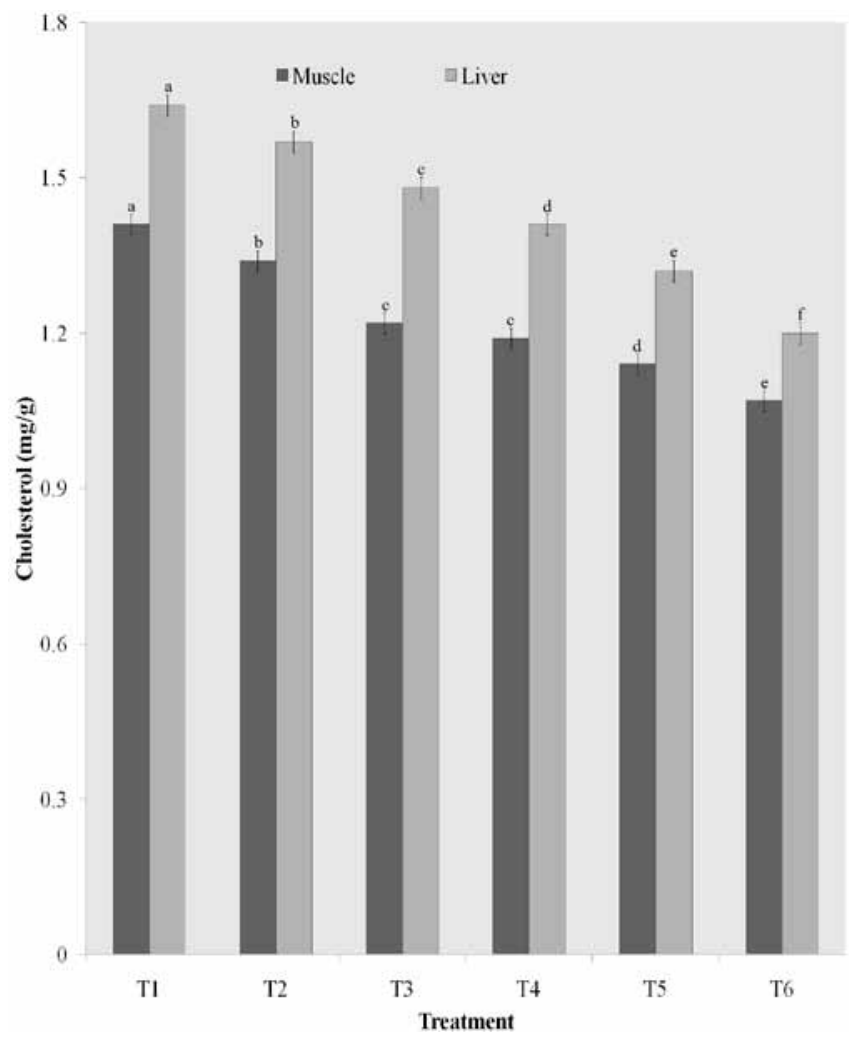

Figure 3: Cholesterol (mg/g tissue) in muscle and liver of $L$. rohita fingerling fed with different experimental diet. Mean values with different superscript differ significantly $(p<0.05)$.

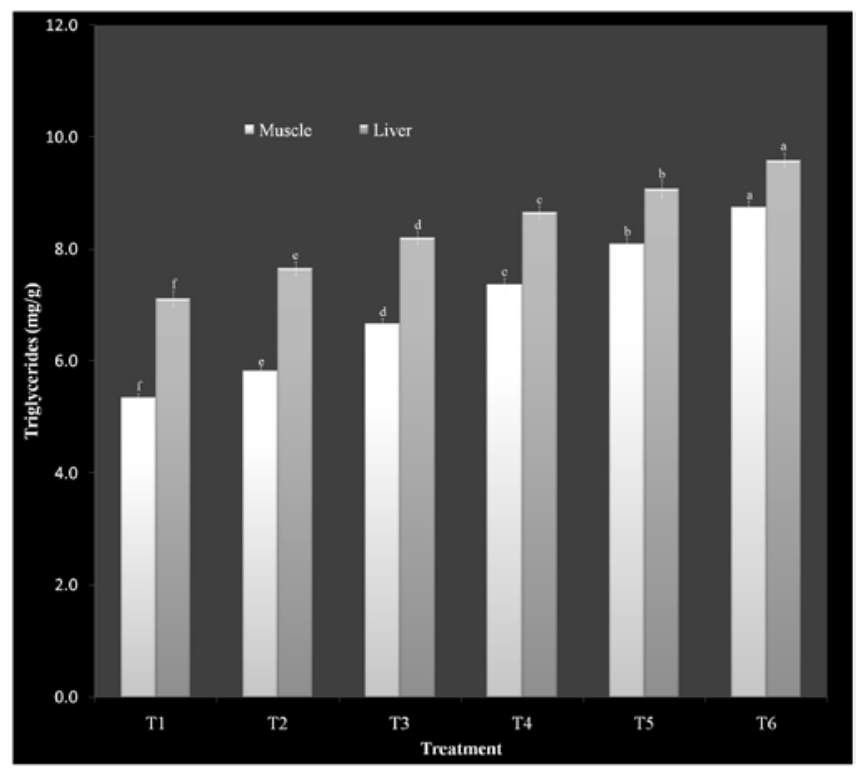

Figure 4: Triglycerides (mg/g tissue) in Muscle and Liver of $L$. rohita fingerling fed with different experimental diet. Mean values with different superscript differ significantly $(p<0.05)$.

level of $\mathrm{G}$ and $\mathrm{NG}$ starch in the diet. In L. rohita juveniles, dietary G starch gives more available carbohydrate, which is utilized for lipogenesis. Hence, increased amounts available carbohydrate favors lipogenesis and consequently leads to an increased proportion of saturated fat compared to the higher deposition of polyunsaturated fatty acids from fat. It is in agreement with [20]. In ayu (Plecoglossus altivelis), [21] had reported that increasing dietary a-starch (nongelatinized) resulted a gradual increase in $n-3$ fatty acids and decrease in n-6 fatty acids which is debatable with our findings where EPA, DHA and total n-3 fatty acids in liver decreased linearly with the increasing level of $\mathrm{G}$ starch in the experimental diet. This controversy may be due to catabolisation via $\beta$ oxidation [27-29]. The present data explain that arachidonic acid (ARA) did not show any conclusive relation with degree of gelatinisation. To date there are no reports supporting the effect of starch gelatinisation on arachidonic acid content.

Moreover, saturated fatty acids (SAFA) in liver increased with the increasing level of $\mathrm{G}$ starch in the experimental diet. This may be due to excess energy available through $\mathrm{G}$ starch is converted to saturated fatty acids, is in tune with $[20,17]$ who reported that lower concentrations of n-3 fatty acids and higher concentrations of saturated fatty acids in the neutral lipid fraction of the muscle of fish due to feeding of gelatinized starch. Whereas, total n-6 fatty acids in liver decreased with increasing level of $\mathrm{G}$ starch. Indeed, saturated and monounsaturated fatty acids are less susceptible to lipid oxidation than poly unsaturated fatty acids, particularly n-3 fatty acids [30,31].

Lipids represent a diverse group of chemical compounds and the main recognized groups include triglycerides, phospholipids and cholesterol. Our result showed that in liver and muscle the total lipid and triglycerides content were increased with increase in the G starch level in the diet. It also demonstrated that incorporation of $G$ corn in diet increased the total lipid content of liver and muscle of $L$. rohita juvenile. It may be correlated with the observation of [32], who reported that in gilthead sea bream (Sparus aurata) lipid content was significantly affected with diets containing extruded cereals resulting in higher lipid content than those containing the raw ones. Hitherto only 
Citation: Kumar V, Sahu NP, Pal AK, Jain KK, Kumar S, et al. (2011) Gelatinized and Non-Gelatinized Corn Starch Based Diet Influence the Fatty Acid Profile in the Liver of Tropical Freshwater Fish, Labeo Rohita. J Aquac Res Development 2:106. doi:10.4172/2155-9546.1000106

Page 6 of 6

cursory attention has been devoted to elucidate the dietary relationship of G/NG carbohydrate with lipid and its different form.

From the present study it can be concluded that both $\mathrm{G}$ and NG starch content affects the total lipid and fatty acids profile of liver. G starch in the diet of $L$. rohita gives more available of carbohydrate which leads to synthesis of more total lipid. Hence, fatty acids are more influenced by $G$ starch in the diet. However, NG starch in the diet induces more deposition of n-3 fatty acids, which seems to be interesting. Among n-3 fatty acids EPA and DHA content significantly decreases with increasing level of $\mathrm{G}$ starch in the diet. This study implies that type of starch significantly influences the fatty acids type and tissue lipid profile of $L$. rohita. Hence dietary starch (NG/G) should be considered as a source for the modification of liver fatty acid profiles and thus a strategy for quality improvement.

\section{Acknowledgements}

The authors are grateful to the Director, Central Institute of Fisheries Education, Mumbai, for providing facilities for carrying out the work. The first author is grateful to Central Institute of Fisheries Education, Mumbai for awarding the institutional fellowship.

\section{References}

1. Ling S, Kuah MK, Tengku Muhammad TS, Kolkovski S, Shu-Chien AC (2006) Effect of dietary HUFA on reproductive performance, tissue fatty acid profile and desaturase and elongase mRNAs in female swordtail Xiphophorus heller . Aquaculture 261:204-214.

2. Zheng X, Seiliez I, Hastings N, Tocher DR, Panserat S, at al. (2004) Characterization and comparison of fatty acyl $\Delta 6$ desaturase cDNAs from freshwater and marine teleost fish species. Comparative Biochemistry and Physiology Part B 139:269-279.

3. Rincon-Sanchez AR, Hernandez A, Lopez ML, Mendoza-Figueroa T (1992) Synthesis and secretion of lipids by long-term cultures of female rat hepatocytes. Biology of the Cell 76:131-138.

4. Rainuzzo JR, Reitan KI, Jorgensen L, Olsen Y (1994) Lipid composition in turbot larvae fed live feed cultured by emulsions of different lipid classes. Comparative Biochemistry and Physiology 107:699-710.

5. Ackman RG, Mcleod C, Rakshit S, Misra KK (2002) Lipids and fatty acids of five freshwater food fishes of India. Journal of Food Lipids 9:127-145.

6. De Silva SS, Anderson TA (1995) Fish Nutrition in Aquaculture. Chapman and Hall, London

7. Jauncey K (1982) The effect of varying dietary protein level on the growth food conversion, protein utilization and body composition of juvenile tilapias (Sarotherodon mossambicus). Aquaculture 27:43-54.

8. Roberts RJ, Bullock AM (1989) The nutritional pathology of fishes. In: J. E. Halver (ed.). Academic Press, London, pp. 423-473.

9. Roberts RJ (1989) Nutritional pathology of teleosts. In:R. J. Roberts (ed.), Fish Pathology. Bailliere Tindall, London, pp. 337-362.

10. Lall SP (1991) Salmonid nutrition and feed production. In: R. H. Cook, W. Pennel (eds), Proceedings of the Special Session on Salmonid Aquaculture. World Aquaculture Society, Los Angeles, CA: pp. 107-123.

11. Mohapatra M, Sahu NP, Chaudhari A (2003) Utilization of gelatinized carbohydrate in diets in Labeo rohita fry. Aquaculture Nutrition 9:189-196.

12. Misra S, Sahu NP, Pal AK, Xavier B, Kumar S, et al. (2006) Pre- and postchallenge immuno-haematological changes in Labeo rohita juveniles fed gelatinised or non-gelatinised carbohydrate with n-3 PUFA. Fish and Shellfish Immunology 21:346-356.

13. Kumar S, Sahu NP, Pal AK, Choudhury D, Mukherjee SC (2006a) Non- gelatinized corn supplemented with a-amylase at sub-optimum protein leve enhances the growth of Labeo rohita (Hamilton) fingerlings. Aquaculture Research 37:284-292.

14. Kumar S, Sahu NP, Pal AK, Choudhury D, Mukherjee SC (2006b) Studies on digestibility and digestive enzyme activities in Labeo rohita (Hamilton) juveniles: effect of microbial $\alpha$-amylase supplementation in non-gelatinized or gelatinized corn-based diet at two protein levels. Fish Physiology and Biochemistry 32:209-220.

15. Kumar V, Sahu NP, Pal AK, Kumar S (2007) Immunomodulation of Labeo rohita juveniles due to dietary gelatinized and non-gelatinized starch. Fish and Shellfish Immunology 23:341-353.

16. Kumar V, Sahu NP, Pal AK, Kumar S, Gupta SK (2008a) Gelatinized to nongelatinized starch ratio in the diet of Labeo rohita: effect on digestive and metabolic response and on growth. Journal of Animal Physiology and Animal Nutrition 92:492-501.

17. Kumar V, Sahu NP, Pal AK, Kumar S, Sharma P, et al. (2008b) Non-gelatinized starch influences the deposition of n-3 fatty acids in the muscle of a tropical fresh water fish Labeo rohita. Journal of Animal Physiology and Animal Nutrition 93(5):659-68

18. Webster CD, Lim C (2002) Nutrient requirements and feeding of aquaculture fish, 418 pp. (Webester, C. D. and C. Lim., Eds.). New York: CAB international Publishers.

19. Chiou JY, Ogino C (1975) Digestibility of starch in carp. Bull. Jpn. Soc. Sci. Fish 41:465-466

20. Alvarez MJ, Lopez-Bote CJ, Diez A, Corraze G, Arzel J, et al. (1999) The partia substitution of digestible protein with gelatinized starch as an energy source reduces susceptibility to lipid oxidation in rainbow trout (Oncorhynchus mykiss) and sea bass (Dicentrarchus labrax) muscle. Journal of Animal Science 77:3322-3329.

21. Nakagawa H, Furuhashi M, Umino T, Takago A, Sakamoto S (2004) Utilization of a-starch in ayu, Plecoglossus altivelis, relating to growth and body composition. Journal of Applied Ichthyology 20:389-394.

22. AOAC (1995) In: P. A. Cunniff (ed.), official methods of analysis of AOAC International, Vol. 1, 16th edn. AOAC International, Arlington, USA.

23. Folch J, Lees M, Sloane-Stanley GH (1957) A simple method for the isolation and purification of total lipids from animal tissues. Journal of Biological Chemistry 226:497-509

24. Marsh JV, Weinstein DV (1966) Simple charring method for determination of lipids. Journal of Lipid Research 7:574.

25. Wanger $H$, Lissan A, Holze J, Herhanmer L (1962) The incorporation of $P 32$ into the inositol phosphatides of the rate brain. Journal of Lipid Research 3:177-180.

26. Zlatkis A, Zak B, Boyl AJ (1953) A new method for direct determination of serum cholesterol. Journal of Laboratory and Clinical Medicine 41:486-492.

27. Henderson RJ (1996) Fatty acid metabolism in freshwater fish with particular reference to polyunsaturated fatty acids. Archives of Animal Nutrition 49:5-22.

28. Henderson RJ, Sargent JR (1985) Chain length specificities of mitochondria and peroxisomal $\beta$-oxidation of fatty acids in livers of rainbow trout. Comparative Biochemistry and Physiology 82B:281-347.

29. Sargent JR, Tocher DR, Bell JG (2002) The Lipids. In: J. E. Halver, R. W. Hardy (eds), Fish Nutrition, $3^{\text {rd }}$ edn. Academic Press, San Diego, CA, pp. 181-257.

30. Austreng E, Krogdahl A (1987) Food quality of cultured salmonids can be influenced. Feedstuffs 59:12-14.

31. Lopez-Bote CJ, Rey AI, Sanz M, Gray JI, Buckley JD (1997) Dietary vegetable oils and a-tocopherol reduce lipid oxidation in rabbit muscle. The Journal of Nutrition 127:1176-1182.

32. Venou B, Alexis MN, Fountoulaki E, Nengas I, Apostolopoulou M, et al. (2003) Effect of extrusion of wheat and corn on gilthead sea bream (Sparus aurata) growth, nutrient utilization efficiency, rates of gastric evacuation and digestive enzyme activities. Aquaculture 225:207-223. 